\section{Original Article}

Korean J Transplant 2021;35:218-229 https://doi.org/10.4285/kjt.21.0024
Received October 5, 2021

Revised December 2, 2021

Accepted December 3, 2021

Corresponding author: Terence Kee Department of Renal Medicine, Singapore General Hospital, Level 3, The Academia, 20 College Rd, Singapore 169586,

Singapore

Tel: +65-63214436

Fax: $+65-63214436$

E-mail: terence.kee.y.s@singhealth.com.sg

(c) The Korean Society for Transplantation This is an Open Access article distributed under the terms of the Creative Commons Attribution Non-Commercial License (http://creativecommons.org/licenses/ by-nc/4.0/) which permits unrestricted non-commercial use, distribution, and reproduction in any medium, provided the original work is properly cited.

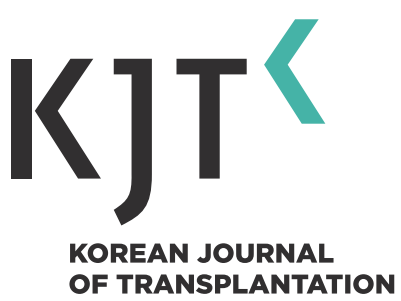

pISSN 2671-8790

eISSN 2671-8804

\title{
Clinical characteristics, outcomes, and management of COVID-19 in kidney transplant recipients across Asia: an ASTREGO report
}

Terence Kee ${ }^{1}$, Jong Cheol Jeong ${ }^{2}$, Harun Ur-Rashid ${ }^{3}$, Nura Afza Salma Begum³ Mel-Hatra Arakama ${ }^{4}$, Romina Danguilan ${ }^{4}$, Lkhaahuu Od-Erdene ${ }^{5}$, Rosnawati Yahya ${ }^{6}$, Yaerim $\mathrm{Kim}^{7}$, Hersharan Kaur Sran ${ }^{8}$, Becky Ma ${ }^{9}$, Maggie Ma ${ }^{9}$, Devinder Singh Rana ${ }^{10}$, Curie Ahn ${ }^{11}$, Ghazali Ahmad ${ }^{12}$

\footnotetext{
${ }^{1}$ Department of Renal Medicine, Singapore General Hospital and Kidney Transplant Program, SingHealth Duke-National University of Singapore Transplant Centre, Singapore

${ }^{2}$ Department of Internal Medicine, Seoul National University Bundang Hospital, Seongnam, Korea

${ }^{3}$ Department of Nephrology, Kidney Foundation Hospital and Research Institute, Dhaka, Bangladesh

${ }^{4}$ Department of Nephrology, National Kidney and Transplant Institute, Quezon, Philippines

${ }^{5}$ Organ Transplantation Center, First Central Hospital, Ulaanbaatar, Mongolia

${ }^{6}$ Department of Nephrology, Kuala Lumpur Hospital, Kuala Lumpur, Malaysia

${ }^{7}$ Department of Internal Medicine, Keimyung University School of Medicine, Daegu, Korea

${ }^{8}$ National University Centre for Organ Transplantation, National University Hospital, Singapore

${ }^{9}$ Department of Medicine, Queen Mary Hospital, Hong Kong

${ }^{10}$ Institute of Renal Sciences, Sir Ganga Ram Hospital, Delhi, India

${ }^{11}$ Department of Nephrology, Seoul National University College of Medicine, Seoul, Korea

${ }^{12}$ Department of Cardiology, National Heart Institute, Kuala Lumpur, Malaysia
}

Background: Asia is the global epicenter of the coronavirus disease 2019 (COVID-19) pandemic; however, COVID-19-related mortality in Asia remains lower than in other parts of the world. It is uncertain whether the mortality of COVID-19-infected kidney transplant recipients (KTXs) from Asia follows the lower mortality trends of the younger Asian population. Methods: Specific transplant centers from countries in the Asian Society of Transplantation were invited to participate in a study to examine the epidemiology, clinical features, natural history, and outcomes of COVID-19 infections in KTXs. Data were analyzed and compared with those of large cohort studies from other countries.

Results: The study population was $87 \mathrm{KTXs}$ from nine hospitals in seven Asian countries. Within the study population, $9 \%$ were aged 60 years and older, and $79 \%$ had at least one comorbidity. The majority of patients (69\%) presented with mild-to-moderate COVID-19 severity. Disease progression was more frequently encountered among those with moderate or severe infection (23\%) and non-survivors (55\%). The mortality rate was $23 \%$ $(n=20)$ and differed according to the level of care: 12\% $(n=1 / 8), 15 \%(n=10 / 67)$, and $100 \%$ $(n=9 / 9)$ of patients managed as outpatients, in the general ward, and in the intensive care unit, respectively. Disease severity at the time of presentation was an independent predictor of mortality. Compared with the mortality rates in other studies worldwide, mortality rates in the current study were comparable.

Conclusions: Mortality in Asian KTXs who were infected with COVID-19 remains high and could be related to comorbidity burden and the constraints of the general healthcare system when the COVID-19 caseload is high.

Keywords: Kidney transplantation; COVID-19; Asia; Registry 


\section{HIGHLIGHTS}

- This is the first multi-national Asian study of coronavirus disease 2019 (COVID-19) infections.

- The study population comprised of younger kidney transplant recipients with a lower comorbidity burden.

- Asymptomatic patients were frequent, but progression to more severe disease was uncommon.

- Mortality from COVID-19 remained high despite a population likely to have a lower risk of progression.

- There may be other factors affecting mortality in Asia such as timely access to higher levels of care.

\section{INTRODUCTION}

Since the coronavirus disease 2019 (COVID-19) pandemic was declared on March 11, 2020, nations around the world have struggled to contain the spread of severe acute respiratory syndrome coronavirus 2 (SARS-CoV-2) while striving for socioeconomic stability. This has become increasingly difficult with recurrent waves of more contagious SARSCoV-2 variants and sluggish vaccination programs. As of December 1, 2021, there are 82,141,978 cases of COVID-19 in Asia. This represents the highest case load among all continents, thus making Asia the new global epicenter of COVID-19.

Many transplant programs in Asia were either shut down or overwhelmed by the increasing incidence of COVID-19 cases; therefore, transplantation in Asia, which is a region with already low transplantation rates, was dealt another huge blow by the COVID-19 pandemic [1]. However, there is paucity of data on morbidity and mortality from COVID-19 involving transplant recipients in Asia. In a systematic review of studies of COVID-19 in kidney transplant recipients (KTXs), only 10 out of 38 studies $(26 \%)$ were from Asia [2]. Given that the mortality and morbidity of COVID-19 in KTXs is appreciably high, more studies from Asia are urgently required [3].

The Asian Society of Transplantation (AST), which is supported by the Korean Organ Transplant Registry, established an Asian Organ Transplantation Registry (ASTREG) in 2017 [4]. Data were collected from over 800 patients in Asia [4]. In 2020, a sub-registry task force was formed by a group of researchers (referred to as ASTREGO for ASTREG Research Group) to collect data on COVID-19 infections in Asian KTXs.
This multi-center retrospective observational study is a by-product of ASTREGO and aimed to provide insights into the characteristics, clinical phenotype, and management of COVID-19 in KTXs from transplant programs in various countries in Asia.

\section{METHODS}

This was a retrospective study that used a COVID-19 database developed by Dr. Terence Kee and Dr. Jong Cheol Jeong; this database was also disseminated to specific transplant programs from member countries of the AST. Some transplant centers from Bangladesh, Hong Kong, Mongolia, Malaysia, the Philippines, South Korea, and Singapore agreed to participate and form ASTREGO. Each center obtained approval from their own local institutional review boards and/or patients to collect data on COVID-19-infected KTXs who were admitted in their hospitals.

The inclusion criteria included adult KTXs (age $>18$ years) who were diagnosed with SARS-CoV-2 infection by reverse-transcription polymerase chain reaction (PCR) testing of nasopharyngeal and/or oropharyngeal samples from January 1, 2020, to June 30, 2021. Patients were followed up until June 30,2021 , or until they recovered or died. Data were extracted from medical records on demographic characteristics such as age, sex, type of kidney donor, transplant duration, comorbidities, and immunosuppressive regimen at the time of COVID-19 diagnosis. Information on COVID-19 epidemiology and phenotype, such as source of infection, symptomatology, complications, radiological features, and treatment, was also collected.

Each patient's presentation was stratified according to the severity categories defined by the National Institutes of Health (https://www.covid19treatmentguidelines.nih. gov/overview/clinical-spectrum/): (1) asymptomatic or pre-symptomatic; (2) mild: having symptoms but without dyspnea or abnormal chest radiology; (3) Moderate: symptoms that included clinical evidence of lower respiratory tract disease or abnormal chest radiology but pulse oximetry $>94 \%$ on room air; (4) severe: evidence of severe respiratory tract disease such as pulse oximetry $<94 \%$ on room air, $\mathrm{PaO}_{2} / \mathrm{FiO}_{2}<300 \mathrm{mmHg}$, respiratory rate $>30$ breaths per minute, or lung infiltrates seen on $>50 \%$ of imaging; (5) critical: presence of respiratory failure, septic shock, and/ or multi-organ dysfunction. The collected data were also 
compared between survivors and non-survivors to identify the risk factors associated with mortality.

\section{Statistical Analysis}

Continuous variables are presented as medians and ranges, and categorical variables are reported as frequencies and percentages. The chi-square test and Wilcoxon rank-sum test were used to compare the characteristics and outcomes between survivors and non-survivors. To determine the risk factors for mortality from COVID-19 infections, a multivariate analysis of baseline characteristics was performed using logistic regression analysis. The variables included in the logistic regression analysis model were age 60 years and older, female sex, presence of comorbidities, transplant duration less than 1 year, and disease severity at the time of presentation. Results from the multivariate analysis were presented as odds ratios with $95 \%$ confidence intervals. Differences were considered significant if the P-value was less than 0.05 . Statistical analyses were performed using IBM SPSS ver. 26.0 (IBM Corp., Armonk, NY, USA). The clinical and research activities reported here are consistent with the principles of the Declaration of Istanbul.

\section{RESULTS}

\section{Demographic Characteristics}

Nine transplant centers from seven Asian countries participated in this study. The study population consisted of 87 patients who tested positive for SARS-CoV-2 from March 1, 2020, to May 19, 2021. The centers participating in the study included the Kidney Foundation Hospital and Research Institute (Bangladesh), National Transplant and Kidney Institute (Philippines), First Central Hospital (Mongolia), Hospital Kuala Lumpur (Malaysia), Queen Elizabeth Hospital (Malaysia), Seoul National Bundang Hospital (South Korea), Singapore General Hospital (Singapore), National University Hospital (Singapore), and Queen Mary Hospital (Hong Kong). Over $50 \%$ of the study population included patients from Bangladesh $(32 \%, \mathrm{n}=28)$, the Philippines $(16 \%, n=14)$, South Korea $(3 \%, n=3)$, Singapore $(2 \%$, $\mathrm{n}=2)$, and Hong Kong $(1 \%, \mathrm{n}=1)$. All patients received a kidney transplant alone, except one who received a simultaneous kidney-pancreas transplant.

Table 1 shows the baseline characteristics of the study population. The median age of infected KTXs was 43 years (range, 21-80 years), and only $9 \%$ of patients were 60 years of age or older. Most of the patients were male (72\%) and were recipients of living donor kidney transplants (79\%). The median time from transplant to presentation was 5 years (range, 5 days -27 years), and the median duration of follow-up for COVID-19 infection was 19 days (range, 3-162 days). Patients who were infected within 1 year of transplant surgery represented $12 \%$ of the study population, with one case of infection occurring within 5 days of transplant surgery because of nosocomial transmission.

The median estimated glomerular filtration rate (eGFR) at the time of presentation of COVID-19 was $40 \mathrm{~mL} / \mathrm{min} / 1.73 \mathrm{~m}^{2}$ (range, 6-93) among 33 patients whose baseline eGFR value was available. Three patients (3.4\%) presented with renal allograft failure (defined as eGFR $<15 \mathrm{~mL} / \mathrm{min} / 1.73 \mathrm{~m}^{2}$ ). When all these parameters were compared between survivors and non-survivors, the only significant difference observed was a lower median eGFR among the non-survivors than the survivors ( 28 vs. $45 \mathrm{~mL} / \mathrm{min} / 1.73 \mathrm{~m}^{2}, \mathrm{P}=0.003$ ). There was also a greater proportion of non-survivors who were older than 60 years ( $15 \%$ vs. $7 \%)$ and with a transplant duration of less than 1 year (15\% vs. $10 \%)$. However, these differences were not statistically significant.

At the end of the study follow-up, $17 \%(n=15 / 87)$ of patients were reported to not have cleared their COVID-19 infection as defined by the clinical resolution of symptoms with or without a negative PCR result. In 29 patients who recovered from COVID-19 with available results from repeat PCR testing for SARS-CoV-2, the median time to a negative PCR result was 31 days (range, 4-31 days). With respect to comorbidity burden, $79 \%$ had at least one comorbidity (Table 1). The community transmission of COVID-19 is the most common route of transmission of infection.

\section{Clinical Presentation and Progression of COVID-19}

Within the ASTREGO population, data on clinical presentation were not available for 12 patients (14\%), whereas another 13 patients (15\%) were asymptomatic when tested positive for SARS-CoV-2 as part of the protocol screening. For the remaining 62 patients $(71 \%)$, the most common presenting symptoms of COVID-19 infection were cough $(66 \%)$, fever (63\%), and loss of appetite (48\%) (Table 2). Fever and headache were the most frequent symptoms among the non-survivors. Interestingly, arthralgia, palpitations, and orbital cellulitis were rare presentations in three patients. 
Kee T et al. COVID-19 infections in Asian kidney transplants

Table 1. Baseline characteristics of the study population

\begin{tabular}{|c|c|c|c|c|}
\hline Variable & All $(n=87)$ & Survivor $(n=67)$ & Non-survivor $(n=20)$ & P-value \\
\hline Age (yr) & $43(21-80)$ & $43(21-64)$ & $45(32-80)$ & 0.470 \\
\hline Age $\geq 60 \mathrm{yr}$ & $8(9)$ & $5(7)$ & $3(15)$ & 0.306 \\
\hline Sex & & & & 0.768 \\
\hline Male & $63(72)$ & $48(72)$ & $15(75)$ & \\
\hline Female & $24(28)$ & $19(28)$ & $5(25)$ & \\
\hline Type of donor & & & & 0.584 \\
\hline Living & $69(79)$ & $52(78)$ & $17(85)$ & \\
\hline Deceased & $15(17)$ & $13(19)$ & $2(10)$ & \\
\hline Unknown & $3(3)$ & $2(3)$ & $1(5)$ & \\
\hline Time after transplantation (yr) & $5(0.01-27)$ & $5(0.01-27)$ & $5(4-25)$ & 0.790 \\
\hline Time after transplantation $<1 \mathrm{yr}$ & $10(12)$ & $7(10)$ & $3(15)$ & 0.744 \\
\hline Lymphocyte depleting antibody exposure & $8(9)$ & $5(7)$ & $3(15)$ & 0.306 \\
\hline Calcineurin Inhibitor & & & & 0.718 \\
\hline Tacrolimus & $76(87)$ & $59(88)$ & $17(85)$ & \\
\hline Cyclosporine & $11(13)$ & $8(12)$ & $3(15)$ & \\
\hline Corticosteroids & $79(91)$ & $61(91)$ & $18(90)$ & 0.887 \\
\hline Anti-metabolite & & & & 0.915 \\
\hline Mycophenolic acid & $58(67)$ & $44(66)$ & $14(70)$ & \\
\hline Azathioprine & $4(5)$ & $3(4)$ & $1(5)$ & \\
\hline None & $25(29)$ & $20(30)$ & $5(25)$ & \\
\hline mTOR inhibitor & $3(3)$ & $3(4)$ & 0 & 0.336 \\
\hline Comorbidity burden & & & & 0.583 \\
\hline No comorbidity & $18(21)$ & $13(19)$ & $5(25)$ & \\
\hline 1-2 Comorbidity & $60(69)$ & $48(72)$ & $12(60)$ & \\
\hline$>2$ Comorbidity & $9(10)$ & $6(9)$ & $3(15)$ & \\
\hline Hypertension & $46(53)$ & $35(52)$ & $11(55)$ & 0.828 \\
\hline Diabetes mellitus & $19(22)$ & $13(19)$ & $6(30)$ & 0.314 \\
\hline Chronic lung disease/asthma & $18(21)$ & $13(19)$ & $5(25)$ & 0.588 \\
\hline Obesity & $13(15)$ & $10(15)$ & $3(15)$ & 0.993 \\
\hline Cardiovascular disease & $11(13)$ & $6(9)$ & $5(25)$ & 0.058 \\
\hline Chronic liver disease & $5(6)$ & $5(7)$ & 0 & 0.208 \\
\hline Cancer & $3(3)$ & $3(4)$ & 0 & 0.336 \\
\hline eGFR at the time of presentation $\left(\mathrm{mL} / \mathrm{min} / 1.73 \mathrm{~m}^{2}\right)$ & $40(6-93)$ & $45(24-93)$ & $28(6-92)$ & 0.003 \\
\hline Source of COVID-19 exposure & & & & 0.855 \\
\hline Community acquired & $55(63)$ & $42(63)$ & $13(65)$ & \\
\hline Household cluster & $17(19)$ & $12(18)$ & $5(25)$ & \\
\hline Workplace cluster & $8(9)$ & $7(10)$ & $1(5)$ & \\
\hline Healthcare cluster & $6(7)$ & $5(7)$ & $1(5)$ & \\
\hline Imported or overseas & $1(1)$ & $1(1)$ & 0 & \\
\hline
\end{tabular}

Values are presented as median (range) or number (\%).

mTOR, mammalian target of rapamycin; eGFR, estimated glomerular filtration rate; COVID-19, coronavirus disease 2019.

Chest X-ray data were available for 71 patients. A normal chest radiograph was the most common finding observed in $49 \%$ of the cases and was more frequent among survivors than among non-survivors (58\% vs. $19 \%$, $\mathrm{P}=0.004$ ) (Table 2). Pulmonary consolidation was the second most common abnormality (32\%), but it was more fre- 
Table 2. Symptoms and radiological features of COVID-19 infections

\begin{tabular}{|c|c|c|c|c|}
\hline Variable & All $(n=62)$ & Survivor $(n=48)$ & Non-survivor $(n=14)$ & P-value \\
\hline Cough & $41(66)$ & $31(65)$ & $10(71)$ & 0.634 \\
\hline Fever & $39(63)$ & $26(54)$ & $13(93)$ & 0.008 \\
\hline Loss of appetite & $30(48)$ & $21(44)$ & $9(64)$ & 0.176 \\
\hline Fatigue & $26(42)$ & $19(40)$ & $7(50)$ & 0.487 \\
\hline Myalgia & $19(31)$ & $14(29)$ & $5(35)$ & 0.640 \\
\hline Headache & $16(26)$ & $8(17)$ & $8(57)$ & 0.002 \\
\hline Anosmia & $15(24)$ & $10(21)$ & $5(36)$ & 0.253 \\
\hline Loss of taste & $15(24)$ & $12(25)$ & $3(21)$ & 0.784 \\
\hline Dyspnea & $13(21)$ & $9(19)$ & $4(29)$ & 0.427 \\
\hline Sputum production & $13(21)$ & $10(21)$ & $3(21)$ & 0.962 \\
\hline Sore throat & $13(21)$ & $10(21)$ & $3(21)$ & 0.962 \\
\hline Nausea & $12(19)$ & $7(15)$ & $5(36)$ & 0.078 \\
\hline Altered mental status & $11(18)$ & $7(15)$ & $4(29)$ & 0.228 \\
\hline Diarrhea & $9(14)$ & $7(15)$ & $2(14)$ & 0.978 \\
\hline Vomiting & $7(11)$ & $3(6)$ & $4(29)$ & 0.061 \\
\hline Rhinorrhea & $4(6)$ & $4(8)$ & 0 & 0.264 \\
\hline Abdominal pain & $3(5)$ & $2(4)$ & $1(7)$ & 0.648 \\
\hline Other symptom & & & & 0.346 \\
\hline Arthralgia & $1(2)$ & $1(2)$ & 0 & \\
\hline Palpitations & $1(2)$ & 0 & $1(7)$ & \\
\hline Orbital Cellulitis & $1(2)$ & 0 & $1(7)$ & \\
\hline \multicolumn{5}{|l|}{ Chest $\mathrm{X}$-ray finding ${ }^{\mathrm{a})}$} \\
\hline No abnormality & $35(49)$ & $32(58)$ & $3(19)$ & 0.004 \\
\hline Consolidation & $23(32)$ & $14(25)$ & $9(56)$ & 0.037 \\
\hline Pleural effusion & $9(13)$ & $5(9)$ & $4(25)$ & 0.169 \\
\hline Ground glass opacity & $4(6)$ & $4(7)$ & 0 & 0.286 \\
\hline \multicolumn{5}{|c|}{ Computed tomography chest finding ${ }^{\text {b) }}$} \\
\hline No abnormality & $23(55)$ & $19(59$ & $4(40)$ & 0.283 \\
\hline Ground glass opacities & $8(19)$ & $6(19)$ & $2(20)$ & 0.365 \\
\hline Pleural effusion & $5(12)$ & $3(9)$ & $2(20)$ & 0.240 \\
\hline Reticular or lobular thickening & $4(9)$ & $4(12)$ & 0 & 0.930 \\
\hline Pulmonary nodule & $2(5)$ & 0 & $2(20)$ & 0.010 \\
\hline
\end{tabular}

Values are presented as number (\%).

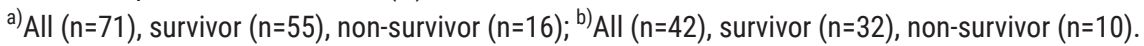

quently found in non-survivors than in survivors (56\% vs. $25 \%, P=0.037)$.

In terms of disease severity (Table 3 ), the majority of patients $(69 \%)$ presented with mild and moderate COVID-19 infections, whereas another $15 \%$ had either asymptomatic or pre-symptomatic infection at the time of presentation. Not surprisingly, a greater proportion of non-survivors had COVID-19 infections of moderate severity $(65 \%$ vs. $39 \%, P=0.039)$ or critical COVID-19 infections (15\% vs. $1 \%, P=0.011)$ than survivors. Progression to more severe COVID-19 infection was also more frequent among non-survivors than among survivors (55\% vs. $10 \%$, $\mathrm{P}<0.005)$. Progression to a more severe disease was associated with the initial disease severity at the time of presentation; $85 \%$ and $90 \%$ of asymptomatic and mildly infected patients did not progress in disease severity, respectively. By contrast, $23 \%$ of patients presenting with COVID-19 infections of moderate severity progressed to a more severe disease, whereas $60 \%$ and $100 \%$ of patients with severe and critical COVID-19 infection remained in the 
Table 3. Severity, complications, and management of COVID-19 infections

\begin{tabular}{|c|c|c|c|c|}
\hline Variable & All $(n=87)$ & Survivor $(n=67)$ & Non-survivor $(\mathrm{n}=20)$ & P-value \\
\hline \multicolumn{5}{|l|}{ Disease severity at time of presentation } \\
\hline Asymptomatic & $13(15)$ & $12(18)$ & $1(5)$ & 0.155 \\
\hline Mild & $21(24)$ & $21(31)$ & 0 & 0.004 \\
\hline Moderate & $39(45)$ & $26(39)$ & $13(65)$ & 0.039 \\
\hline Severe & $10(11)$ & $7(10)$ & $3(15)$ & 0.575 \\
\hline Critical & $4(5)$ & $1(1)$ & $3(15)$ & 0.011 \\
\hline Progression to more severe COVID-19 infection & $18(21)$ & $7(10)$ & $11(55)$ & 0.005 \\
\hline Admission to hospital & $79(91)$ & $60(89)$ & $19(95)$ & 0.459 \\
\hline Admission to the ICU & $9(10)$ & 0 & $9(45)$ & $<0.001$ \\
\hline Oxygen supplementation ${ }^{\text {a) }}$ & $21 / 62(34)$ & $12 / 48(25)$ & $9 / 14(64)$ & 0.025 \\
\hline AKI & $25(29)$ & $11(16)$ & $14(70)$ & $<0.001$ \\
\hline Multi-organ failure & $13(15)$ & 0 & $13(65)$ & 0.005 \\
\hline Respiratory failure requiring ventilation ${ }^{\text {a) }}$ & $9 / 62(14)$ & $1 / 48(2)$ & $8 / 14(57)$ & $<0.001$ \\
\hline Renal replacement therapy ${ }^{\mathrm{a})}$ & $9 / 62(14)$ & $0 / 48(0)$ & $9 / 14(64)$ & $<0.001$ \\
\hline Renal allograft rejection & $10(11)$ & $1(1)$ & $9(45)$ & $<0.001$ \\
\hline Cardiac injury & $7(8)$ & $3(4)$ & $4(20)$ & 0.025 \\
\hline Shock & $7(8)$ & 0 & $7(35)$ & 0.005 \\
\hline Arrhythmias & $5(6)$ & $2(3)$ & $3(15)$ & 0.043 \\
\hline Cytopenias & $3(3)$ & 0 & $3(15)$ & 0.001 \\
\hline Liver injury & $3(3)$ & $2(3)$ & $1(5)$ & 0.665 \\
\hline Thrombosis & $1(1)$ & 0 & $1(5)$ & 0.066 \\
\hline Coagulopathy & $1(1)$ & 0 & $1(5)$ & 0.066 \\
\hline Secondary infections & $4(5)$ & $2(3)$ & $2(10)$ & 0.189 \\
\hline Increased doses of corticosteroids ${ }^{a}$ ) & $41 / 62(66)$ & $30 / 47(64)$ & $11 / 15(73)$ & 0.534 \\
\hline Anticoagulation $^{\text {a) }}$ & $38 / 62(61)$ & $24 / 47(51)$ & $14 / 15(93)$ & 0.003 \\
\hline Antivirals ${ }^{a}$ & $31 / 62(50)$ & $18 / 47(38)$ & $13 / 15(87)$ & 0.001 \\
\hline Antibiotics $^{\mathrm{a})}$ & $28 / 62(45)$ & $18 / 47(38)$ & $10 / 15(67)$ & 0.025 \\
\hline Reduction in immunosuppression ${ }^{a}$ ) & $27 / 62(43)$ & $21 / 47(45)$ & $6 / 15(40)$ & 0.750 \\
\hline Reduction or discontinuation of calcineurin inhibitors & $16 / 62(26)$ & $11 / 47(23)$ & $5 / 15(33)$ & 0.243 \\
\hline Reduction or discontinuation of anti-metabolite & $29 / 62(47)$ & 23/47 (49) & $6 / 15(40)$ & 0.444 \\
\hline Hydroxychloroquine $^{\text {a) }}$ & $12 / 62(19)$ & $8 / 47(17)$ & $4 / 15(27)$ & 0.410 \\
\hline Azithromycin ${ }^{\text {a) }}$ & $10 / 62(16)$ & $6 / 47(13)$ & $4 / 15(27)$ & 0.150 \\
\hline
\end{tabular}

Values are presented as number (\%).

COVID-19, coronavirus disease 2019; ICU, intensive care unit; AKI, acute kidney injury.

${ }^{\text {a) }}$ Data for 25 patients not available.

Table 4. Multivariate analysis of risk factors associated with mortality from COVID-19

\begin{tabular}{|c|c|c|c|}
\hline \multirow{2}{*}{ Variable } & \multicolumn{3}{|c|}{ Multivariate analysis } \\
\hline & OR & $95 \% \mathrm{Cl}$ & P-value \\
\hline$\geq 60 \mathrm{yr}$ & 10.93 & $0.97-122.67$ & 0.053 \\
\hline Female sex & 1.06 & $0.28-3.93$ & 0.933 \\
\hline Transplant duration less than 1 year & 2.01 & $0.40-10.03$ & 0.396 \\
\hline Presence of comorbidities & 0.43 & $0.10-1.76$ & 0.240 \\
\hline Moderate, severe, and critical disease at time of presentation & 41.00 & $3.43-489.56$ & 0.003 \\
\hline
\end{tabular}

COVID-19, coronavirus disease 2019; OR, odds ratio; Cl, confidence interval. 
Table 5. Comparison of clinical characteristics, outcomes, and management with other large cohort studies of COVID-19 in KTXs

\begin{tabular}{|c|c|c|c|c|c|c|}
\hline Variable & $\begin{array}{l}\text { ASTREGO } \\
(n=87)\end{array}$ & $\begin{array}{l}\text { South Asia } \\
(n=250)\end{array}$ & $\begin{array}{l}\text { West Asia } \\
(n=130)\end{array}$ & $\begin{array}{l}\text { Europe } \\
(n=279)\end{array}$ & $\begin{array}{l}\text { North America } \\
\qquad(n=54)\end{array}$ & $\begin{array}{l}\text { South America } \\
\qquad(n=491)\end{array}$ \\
\hline Representative nation & $\begin{array}{l}\text { East and } \\
\text { Southeast Asia }\end{array}$ & India [5] & Saudi Arabia [6] & France [7] & New York [8] & Brazil [9] \\
\hline Age (yr) & $43(21-80)$ & $43(35-51)$ & $48.7 \pm 14.4$ & $\begin{array}{l}\text { Outpatient, } 55.6 \\
\begin{array}{l}(48-61.1) ; \\
\text { inpatient, } 61.6 \\
(50.8-69.0)\end{array}\end{array}$ & $57(29-83)$ & $53(43-60)$ \\
\hline Living donor kidney transplant & 79 & 90 & 80 & NA & 69 & 33 \\
\hline $\begin{array}{l}\text { COVID-19 within the first year } \\
\text { of transplantation }\end{array}$ & 12 & 20 & 16 & 14.4 & $\begin{array}{c}\text { Outpatient, 18; } \\
\text { inpatient, } 13\end{array}$ & 13.8 \\
\hline Hypertension & 53 & 84 & 79 & 80.6 & 93 & 68 \\
\hline Diabetes & 22 & 32 & 45 & 37.2 & 30 & 32 \\
\hline Cardiac disease & 13 & 12 & 17 & 31.2 & 35 & 12 \\
\hline \multicolumn{7}{|c|}{ Most common immunosuppression ${ }^{\text {a) }}$} \\
\hline Calcineurin inhibitor & 100 & 94.4 & 96 & 83.1 & 100 & Tacrolimus \\
\hline Prednisolone & 91 & 100 & 98 & 72.8 & 31.5 & Prednisolone \\
\hline Anti-metabolite & 71 & 100 & 93 & 79.8 & 96.3 & Mycophenolate \\
\hline mTOR inhibitor and others & 3 & 5.6 & 5 & 11.9 & 3.7 & 46 \\
\hline Asymptomatic case & 15 & 6 & 1 & 0 & 0 & 3 \\
\hline Most common symptom & $\begin{array}{l}\text { Cough, 66; } \\
\text { fever, 63; } \\
\text { anorexia, } 30\end{array}$ & $\begin{array}{l}\text { Fever, 88; } \\
\text { cough, 72; } \\
\text { sputum, } 52\end{array}$ & $\begin{array}{c}\text { Fatigue, } 62 ; \\
\text { fever, } 60 ; \\
\text { cough, } 58\end{array}$ & $\begin{array}{l}\text { Fever, 80; } \\
\text { cough, 63.6; } \\
\text { diarrhea, 43.5 }\end{array}$ & $\begin{array}{l}\text { Fever, 74; } \\
\text { cough, 59; } \\
\text { dyspnea, } 52\end{array}$ & $\begin{array}{l}\text { Cough, 62; } \\
\text { fever, 60; } \\
\text { dyspnea, } 51\end{array}$ \\
\hline Radiological abnormality & 50.7 & 51 & 33.1 & 87 & NA & 97.3 \\
\hline Hospital admission & 90.8 & 80 & 55 & 87 & 72 & 69 \\
\hline ICU admission & 10.3 & 21 & 21 & 36 & 33 & 61 \\
\hline Ventilation & 14.5 & 12 & 42 & 30 & 28 & 32 \\
\hline AKI & 28.7 & 48.4 & 27 & 43.6 & 51 & 47 \\
\hline Shock & 8 & NA & 11 & 11 & NA & 29 \\
\hline Secondary infection & 5 & 20 & 29 & 23.5 & 48 & 36 \\
\hline Mortality & 23 & 12 & 11 & 23 & 13 & 28 \\
\hline \multicolumn{7}{|c|}{ Reduction or discontinuation of immunosuppression } \\
\hline Calcineurin inhibitor & 26 & 34 & 35 & 29 & 33 & 1 \\
\hline $\begin{array}{l}\text { Antimetabolite (azathioprine/ } \\
\text { mycophenolic acid) }\end{array}$ & 47 & 98 & 88 & 71 & 72 & 12 \\
\hline Adjustment in corticosteroids & 68 & 40 & 77 & NA & 9 & 2 \\
\hline Azithromycin & 16 & 80 & 31 & 25 & 22 & 45 \\
\hline Hydroxychloroquine & 19 & 64 & 11 & 25 & 62 & 12 \\
\hline Antivirals & 50 & 36 & 20 & 8 & 4 & 0 \\
\hline Antibiotics & 45 & NA & 31 & 63 & 39 & 14 \\
\hline Immunotherapy & 0 & 14 & 5 & 5 & 4 & 0 \\
\hline Convalescent plasma & 0 & 6 & 5 & 0 & 2 & 0 \\
\hline
\end{tabular}

Values are presented as median (interquartile range), mean \pm standard deviation, or percentages.

COVID-19, coronavirus disease 2019; KTX, kidney transplant recipients; ASTREGO, ASTREG research group; NA, data not available; mTOR, mammalian target of rapamycin; ICU, intensive care unit; AKI, acute kidney injury.

a) Data presented from the French study include only those who are hospitalized. 
same disease severity at the end of follow-up, respectively.

Among the asymptomatic patients, one patient was diagnosed with COVID-19 five days after transplant surgery. This patient was tested for SARS-CoV-2 because of contact with a positive COVID-19 case. As a result, the dose of mycophenolate was reduced, and the dose of prednisolone was increased. No allograft rejection occurred, and the patient recovered from the infection with no disease progression.

\section{Complications of COVID-19 Infection}

The majority of patients ( $91 \%$ ) required hospital admission and complications, including acute kidney injury (AKI), respiratory failure, cardiac injury, shock, arrhythmias, multi-organ failure, cytopenia, and renal allograft rejection, which were more frequently encountered in non-survivors than in survivors (Table 3). The need for oxygen supplementation, ventilator support, and renal replacement therapy was also more common in non-survivors than in survivors. The rate of admission to the intensive care unit (ICU) was $10 \%$. The overall mortality rate was $23 \%(n=20)$ and was spread out according to different levels of care: $12 \%(n=1 / 8), 15 \%(n=10 / 67)$, and $100 \%(n=9 / 9)$ of patients managed as outpatients, in the general ward, and in the ICU, respectively. Three patients were admitted to high-dependency units, but none of them died. All graft losses were attributed to the patient's death.

Baseline characteristics were analyzed for predictors of mortality from COVID-19 infection via multivariate analysis (Table 4). Only moderate or more severe disease at the time of presentation was found to be an independent predictor of mortality from COVID-19 infection.

\section{Management of COVID-19}

Data on treatment were available for 62 patients (Table $3)$. The most common COVID-19 specific treatments were corticosteroids (66\%), antivirals (50\%), and reduction of immunosuppression (43\%). Antibiotics were used in $45 \%$ of patients, and there was a high usage of anticoagulants because of local COVID-19 management protocols. Antibiotics, antivirals, and anticoagulation treatments were administered to a greater proportion of non-survivors than survivors.

\section{DISCUSSION}

To the best of our knowledge, this is the first study to examine the clinical characteristics and outcomes of KTXs infected with COVID-19 from three regions of Asia (East, South, and Southeast Asia). The key findings of this study were that those infected were mostly below the age of 60 years; however, the mortality rate remained appreciably high. Notably, $55 \%$ of the mortality occurred in general ward and outpatient settings. Multivariate analysis showed that disease severity at the time of presentation was an independent predictor of mortality.

As of December 1, 2021, Asia has the highest incidence rate (cumulative incidence of 18,009 per million population) of COVID-19 infections worldwide. Despite this high case load, knowledge of COVID-19 infections among Asian KTXs is limited to a few single-center case reports, except for a large multi-center study from India [5]. Expanding COVID-19-related knowledge in Asia is important because most information on COVID-19 in transplant recipients thus far is derived from published studies in other geographical areas that may not necessarily be similar or applicable to the Asian transplant population [10]. One example is information on COVID-19-related mortality, which was observed to be significantly lower in Asia than in Europe (2.7 vs. 197 deaths per million population, $P<0.001)$ [11]. This observation was attributed to a younger population, better national pandemic responses, greater community adherence to social distancing, and wearing of face masks in Asia.

In view of these considerations, the findings of the ASTREGO study were compared with those of other similar studies from India, Saudi Arabia, France, and the Americas (Table 5) [5-9]. The comparisons revealed that the ASTREGO study population and those from India and Saudi Arabia were younger than the European or American study population. Furthermore, the proportion of KTXs aged 60 years and older was significantly lower in the ASTREGO (9\%) and Indian (3.6\%) cohorts than in the United States, Italy, and Spain (56.2\%) [12]. This younger age profile may partly explain the lower frequency of diabetes and heart disease in the ASTREGO and Indian populations. Calcineurin inhibitors were the mainstay of immunosuppression regimens for all cohorts, but steroid-sparing and mammalian target of rapamycin (mTOR) inhibitor-based regimens were more frequently employed in North American and European centers, respectively. However, it remains uncertain whether different immunosuppressive regimens have any 
effect on the natural history and outcomes of COVID-19 infections.

Fever and respiratory symptoms were the most common presenting symptoms in the ASTREGO cohort. These findings were similar to those of other studies on COVID-19-infected KTXs. However, normal chest radiology was frequently observed in the ASTREGO (49.3\%), Indian (49\%), and Saudi Arabian (67.9\%) cohorts despite the dominance of respiratory symptoms. This could be partly attributed to the higher proportion of patients who were asymptomatic or mildly infected in these populations. As a result, radiological findings alone may be insufficient and highlight the need to rely on other assessment tools to stratify patients suspected of having COVID-19. Unfortunately, other assessment methods may not be sufficiently specific and sensitive, particularly in regions where the community prevalence of COVID-19 infections may be high. As a result, the universal swabbing of inpatients for COVID-19 is advocated because COVID-19 can be diagnosed in $1.6 \%$ to $15.4 \%$ of unsuspected patients who were admitted and swabbed [13-16]. Filtering out unsuspected COVID-19 infections by universal swabbing could reduce hospital-acquired COVID-19 infections, which occurred in $6.9 \%$ of the ASTREGO cohort.

Little is known about the natural history of asymptomatic COVID-19 infections in KTXs, as reflected by the small number of asymptomatic cases reported in various studies. In this study, there were 13 asymptomatic patients, which represent $15 \%$ of the study population, but only two patients (15\%) experienced progression of their infections during follow-up. By contrast, the frequency of non-transplant patients who tested for SARS-CoV2 but were asymptomatic can be as high as $56.5 \%$, with progression to symptomatic infections in $31.4 \%$ [17]. Although more studies are required in this area, the low frequency of disease progression in KTXs may suggest that outpatient management is possible in a highly selected group of asymptomatic patients. This would enable hospitals to conserve beds at a higher risk of severe infections. The outpatient management of stable COVID-19-infected KTXs appears to be effective and safe when implemented in the United States, Italy, and France but may otherwise be challenging to implement in some Asian countries because of the lack of telephone and internet access $[7,18,19]$. Another potential problem is prompt access to hospital facilities, which may be difficult in rural parts of Asia, because COVID-19-infected patients who are managed in outpatient settings may eventually require hospitalization at a rate as high as $20 \%$ [6].

In a systematic review of 20 studies, the proportion of patients requiring ICU admission varied from $9 \%$ to $42 \%$ [20]. Therefore, the ICU admission rate in the $10 \%$ ASTREGO cohort was considerably lower. When the ICU admission and secondary infection rates were compared with those of the other cohorts (Table 5), the ASTREGO cohort had the lowest rates. These observations could be explained by a large proportion (87\%) of patients not having severe or critical COVID-19 infections during the course of their illness; however, mortality remained high at $23 \%$, which was not lower than the $18 \%-43 \%$ mortality rates observed in other studies [20]. This may be explained by the high rates of death occurring outside the ICU (75\%), which may have been a surrogate marker of a lack of timely access to the ICU. In studies from India and Saudi Arabia, the mortality rate was lower at $11 \%-12 \%$. This could have been due to the greater proportion of younger patients in their series than that in the ASTREGO cohort $[5,6]$.

This study observed that disease severity at the time of presentation was an independent predictor of mortality, and this finding is consistent with those of other studies where other risk factors include older age, lymphopenia, comorbidities, treatments for rejections/infections, radiological abnormalities, acute respiratory distress syndrome, $\mathrm{AKI}$, admission to ICU, ventilator support, and various biomarkers (e.g., increased levels of inflammatory markers) $[5,6,10,21]$.

It remains uncertain whether immunosuppression may protect against or facilitate the replication of SARS-CoV-2. In vitro studies suggest that calcineurin inhibitors, mammalian target of rapamycin inhibitors, and mycophenolate may inhibit the replication of SARS-CoV-2 [22]. However, systematic reviews suggest that solid organ transplant status is associated with a greater risk of mortality (hazard ratio, 1.54; 95\% confidence interval, 1.03-2.32; $P=0.037$ ) compared with non-solid organ transplant status [23]. This uncertainty may be reflected in diverse approaches to modify immunosuppression during COVID-19 infections. The discontinuation or reduction of calcineurin inhibitors and antimetabolites varied between $1 \%$ to $35 \%$ and $12 \%$ to $98 \%$ of the cohorts examined, respectively (Table 5). A higher proportion of patients from the ASTREGO and Saudi Arabia cohorts had their corticosteroids adjusted (68\%$77 \%$ vs. $2 \%-9 \%$ ) than patients from other regions. Antiviral drug therapies were most often used in the ASTREGO group ( $50 \%$ vs. $0 \%$ to $36 \%$ ), whereas hydroxychloroquine was more frequently used for patients in India and North 
America (62\%-64\%). No patient from the ASTREGO cohort received immunotherapies or convalescent plasma, but this was administered to $2 \%-6 \%$ of patients in other regions. These observations show that there is no consistent approach to the management of COVID-19 in solid organ transplant recipients, but some countries have developed national COVID-19 management protocols to standardize treatments [24]. As a result, this diversity in therapeutic approaches hampers the interpretation of treatment and outcome data.

The major limitation of this study is that not all centers from each country participated, and even within centers, data were incomplete for specific data domains due to the retrospective study design. This was caused by some patients being managed remotely at home, while other investigators had difficulty completing data submissions due to competing demands imposed by increasing COVID-19 workload in their hospitals. In addition, there may have been selection bias in the study population, as not all KTXs infected with COVID-19 would have been screened for SARS-CoV-2. As a result, ASTREGO is still recruiting new collaborators to collect more data on COVID-19-infected transplant recipients so that more accurate interpretations and conclusions can be obtained. Furthermore, the effect of vaccination and monoclonal antibody therapies will also need to be examined in the future as these treatments become more readily available in Asia. Nevertheless, the current study remains valuable because of its focus on COVID-19 infections in KTXs from various regions of Asia and on the regional differences in the phenotype of the infection.

Contrary to the impression that COVID-19 mortality is lower in Asia, this study demonstrated that COVID-19 infection was just as lethal among Asian KTXs as it is in other regions of the world despite the Asian region having a younger population, lower comorbidity burden, and a greater proportion of asymptomatic cases in the ASTREGO cohort. There may be other factors in Asia that influence mortality from COVID-19 infection, such as timely access to higher levels of care, which can be overwhelmed in countries with a high daily caseload of COVID-19 infections. This study also revealed that asymptomatic cases and normal chest radiology may pose challenges in identifying patients for SARS-CoV-2 and proposed a proposition for hospitals to perform surveillance swabs of all patients being admitted to inpatient units. Finally, little is known about asymptomatic COVID-19 infections in KTXs; however, this study reported a low rate of disease progression and suggested that outpatient protocols should be implemented to carefully monitor asymptomatic or mildly infected KTXs at home. Unfortunately, this may be difficult to implement in regions in Asia where telephony and internet penetration are low.

\section{ACKNOWLEDGMENTS}

\section{Conflict of Interest}

Jong Cheol Jeong is an editorial board member of the journal but did not involve in the peer reviewer selection, evaluation, or decision process of this article. No other potential conflicts of interest relevant to this article were reported.

\section{ORCID}

Terence Kee https://orcid.org/0000-0002-2553-766X Jong Cheol Jeong https://orcid.org/0000-0003-0301-7644 Harun Ur-Rashid https://orcid.org/0000-0002-9774-2363 Nura Afza Salma Begum

https://orcid.org/0000-0002-5732-0043

Mel-Hatra Arakama

https://orcid.org/0000-0002-3187-2050

Romina Danguilan

https://orcid.org/0000-0003-3686-417X

Lkhaahuu Od-Erdene

https://orcid.org/0000-0001-9410-6284

Rosnawati Yahya https://orcid.org/0000-0002-1347-5318

Yaerim Kim https://orcid.org/0000-0003-1596-1528 Hersharan Kaur Sran

https://orcid.org/0000-0001-6858-0193

Becky Ma https://orcid.org/0000-0001-9267-7956

Maggie Ma https://orcid.org/0000-0002-7784-8494

Devinder Singh Rana

https://orcid.org/0000-0001-6622-6975

Curie Ahn https://orcid.org/0000-0001-7033-1102

Ghazali Ahmad https://orcid.org/0000-0001-5084-594X

\section{Author Contributions}

Conceptualization: TK, JCJ. Data curation: all authors. Formal analysis: TK, JCJ. Methodology: TK, JCJ. Project administration: TK. Visualization: TK. Writing-original draft: TK. Writing-review \& editing: DSR, CA, GA.

\section{Additional Contributions}

The authors would like to acknowledge the support of their medical teams, who tirelessly cared for COVID-19-infected 
KTXs during the COVID-19 pandemic while assisting in the data recording process.

\section{REFERENCES}

1. Kee T, Jeong JC, Ha J, Rashid HU, Begum NA, Ma MK, et al. Transplantation in Asia during the coronavirus disease-19 (COVID-19) pandemic: briefs from member countries of the Asian Society of Transplantation. Korean J Transplant 2020;34:71-7.

2. Kremer D, Pieters TT, Verhaar MC, Berger SP, Bakker $S J L$, van Zuilen $A D$, et al. A systematic review and meta-analysis of COVID-19 in kidney transplant recipients: lessons to be learned. Am J Transplant 2021;21:393645.

3. Azzi Y, Bartash R, Scalea J, Loarte-Campos P, Akalin E. COVID-19 and solid organ transplantation: a review article. Transplantation 2021;105:37-55.

4. Jeong JC, Yuzawa K, Shroff S, Danguilan R, Koo TY, Thwin KT, et al. Development of the Asian transplant registry under the Asian Society of Transplantation. Transplant Proc 2020;52:1634-8.

5. Kute VB, Bhalla AK, Guleria S, Ray DS, Bahadur MM, Shingare $A$, et al. Clinical profile and outcome of COVID-19 in 250 kidney transplant recipients: a multicenter cohort study from India. Transplantation 2021;105:851-60.

6. Alshaqaq A, Al Abadi A, Altheaby A, Bukhari MA, Alnasrallah B, Alamoudi $A$, et al. Coronavirus disease 2019 and kidney transplantation in Saudi Arabia: outcomes and future opportunities. Ann Transplant 2021;26:e931832.

7. Caillard S, Anglicheau D, Matignon M, Durrbach A, Greze C, Frimat L, et al. An initial report from the French SOT COVID Registry suggests high mortality due to COVID-19 in recipients of kidney transplants. Kidney Int 2020;98:1549-58.

8. Lubetzky M, Aull MJ, Craig-Schapiro R, Lee JR, Marku-Podvorica J, Salinas T, et al. Kidney allograft recipients, immunosuppression, and coronavirus disease-2019: a report of consecutive cases from a New York City transplant center. Nephrol Dial Transplant 2020;35:1250-61.

9. Cristelli MP, Viana LA, Dantas MT, Martins SB, Fernandes R, Nakamura MR, et al. The full spectrum of COVID-19 development and recovery among kidney transplant recipients. Transplantation 2021;105:143344.

10. Fisher AM, Schlauch D, Mulloy M, Dao A, Reyad Al, Correll $\mathrm{M}$, et al. Outcomes of COVID-19 in hospitalized solid organ transplant recipients compared to a matched cohort of non-transplant patients at a national healthcare system in the United States. Clin Transplant 2021;35:e14216.

11. Landoni G, Maimeri N, Fedrizzi M, Fresilli S, Kuzovlev A, Likhvantsev V, et al. Why are Asian countries outperforming the Western world in controlling COVID-19 pandemic? Pathog Glob Health 2021;115:70-2.

12. Cravedi P, Mothi SS, Azzi $Y$, Haverly M, Farouk SS, Pérez-Sáez MJ, et al. COVID-19 and kidney transplantation: results from the TANGO International Transplant Consortium. Am J Transplant 2020;20:3140-8.

13. Sutton D, Fuchs K, D'Alton M, Goffman D. Universal screening for SARS-CoV-2 in women admitted for delivery. N Engl J Med 2020;382:2163-4.

14. Gruskay JA, Dvorzhinskiy A, Konnaris MA, LeBrun DG, Ghahramani GC, Premkumar A, et al. Universal testing for COVID-19 in essential orthopaedic surgery reveals a high percentage of asymptomatic infections. J Bone Joint Surg Am 2020;102:1379-88.

15. Sran K, Olsburgh J, Kasimatis T, Clark K, Gökmen R, Hilton $R$, et al. COVID-19 in kidney transplant patients from a large UK transplant center: exploring risk factors for disease severity. Transplant Proc 2021;53:1160-8.

16. Wee LE, Hsieh JY, Phua GC, Tan Y, Conceicao EP, Wijaya $L$, et al. Respiratory surveillance wards as a strategy to reduce nosocomial transmission of COVID-19 through early detection: the experience of a tertiary-care hospital in Singapore. Infect Control Hosp Epidemiol 2020;41:820-5.

17. Tao PY, Leng L, Liu K, Zhou RH, Hu YC, Wu SJ, et al. Determination of risk factors for predicting the onset of symptoms in asymptomatic COVID-19 infected patients. Int J Med Sci 2020;17:2187-93.

18. Husain SA, Dube G, Morris H, Fernandez H, Chang JH, Paget $\mathrm{K}$, et al. Early outcomes of outpatient management of kidney transplant recipients with coronavirus disease 2019. Clin J Am Soc Nephrol 2020;15:1174-8.

19. Bossini N, Alberici F, Delbarba E, Valerio F, Manenti C, Possenti S, et al. Kidney transplant patients with SARSCoV-2 infection: the Brescia Renal COVID Task Force experience. Am J Transplant 2020;20:3019-29.

20. Mahalingasivam V, Craik A, Tomlinson LA, Ge L, Hou L, Wang Q, et al. A systematic review of COVID-19 and 
kidney transplantation. Kidney Int Rep 2021;6:24-45.

21. Favà $A$, Cucchiari $D$, Montero $N$, Toapanta $N$, Centellas FJ, Vila-Santandreu A, et al. Clinical characteristics and risk factors for severe COVID-19 in hospitalized kidney transplant recipients: a multicentric cohort study. Am J Transplant 2020;20:3030-41.

22. Daoud A, Alqassieh A, Alkhader D, Posadas Salas MA, Rao V, Fülöp T, et al. Immunosuppression in kidney transplant recipients with COVID-19 infection: where do we stand and where are we heading? Ren Fail 2021;43:273-80.

23. Ao G, Wang Y, Qi X, Nasr B, Bao M, Gao M, et al. The association between severe or death COVID-19 and solid organ transplantation: a systematic review and meta-analysis. Transplant Rev (Orlando) 2021;35:100628.

24. Gut G, Góral A, Dal Canton Z, Poznański P, Krajewska M, Kusztal M. Kidney transplantation in COVID pandemic-a review of guidelines. J Clin Med 2021;10:2877. 